66 missings. $90 \%$ of the participants rated app usability good to excellent and $70 \%$ would recommend the app to other patients.

Twelve out of thirty patients generated a total amount of 174 alerts where four patients with a suspicion of gout were responsible for 148 alerts (85\%). These patients scored three out of four criteria as they had warm, swollen and painful joints but, after consultation with the clinician, their symptoms were not regarded as a gout flare.

The 174 alerts belonged to 23 (possible) flares with a median duration of 5 days [IQR 3,5-7,5]. Twenty-one pro-active telephone calls were made which resulted in four visits to the clinic within 48 hours. Clinical guidance over the phone consisted of checking in on patient's symptoms, giving advice and ten medication adjustments.

Conclusion: This prospective study shows feasibility of a smartphone app for home-monitoring gout flares for patients because of high usability scores and low attrition rates. The app has added value for gout care because it enables clinicians to act on flares as they occur. The next step is to further implement the app whilst perpetuating investigation into the added value for patients and clinical practice alike.

References:

[1] Gaffo AL, Dalbeth N, Saag KG, et al. Brief Report: Validation of a Definition of Flare in Patients With Established Gout. Arthritis Rheumatol. 2018;70(3):462-467.

[2] Davis Jr. FD. A Technology Acceptance Model for empirically testing new end-user information systems: theory and results. MIT PhD thesis. 1985

[3] Stoyanov SR, Hides L, Kavanagh DJ, Wilson H. Development and Validation of the User Version of the Mobile Application Rating Scale (uMARS). JMIR Mhealth Uhealth. 2016;4(2):e72.

Acknowledgements: This study was funded by AbbVie and Menarini.

Disclosure of Interests: : Bart Pouls: None declared, Charlotte Bekker: None declared, Bart van den Bemt Grant/research support from: UCB, Pfizer and Abbvie, Consultant of: Delivered consultancy work for UCB, Novartis and Pfizer, Speakers bureau: Pfizer, AbbVie, UCB, Biogen and Sandoz., Angelo Gaffo Grant/research support from: Received a research grant from AMGEN, Marcel Flendrie Grant/research support from: M. Flendrie has received grants from Menarini and Grunenthal., Consultant of: M. Flendrie has received consultancy fees from Menarini and Grunenthal.

DOI: 10.1136/annrheumdis-2020-eular.3643

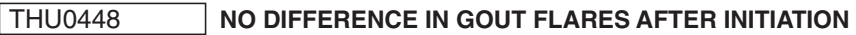 OF URATE LOWERING THERAPY BETWEEN ONCE OR TWICE DAILY 0.5 MG COLCHICINE PROPHYLAXIS}

F. Veenstra ${ }^{1}$, L. M. Verhoef ${ }^{1}$, L. Nieboer ${ }^{1}$, A. Den Broeder ${ }^{1,2}$, W. Y. Kwok ${ }^{3}$, I. Meek ${ }^{2}$, F. Van den Hoogen ${ }^{1,2}$, N. Van Herwaarden ${ }^{1,2}$, M. Flendrie ${ }^{1}$. ${ }^{1}$ Sint Maartenskliniek, Ubbergen, Netherlands; ${ }^{2}$ Radboud University Medical Center, Nijmegen, Netherlands; ${ }^{3}$ Rijnstate, Arnhem, Netherlands

Background: Initiation of urate lowering therapy (ULT) is associated with an increase in gout flares ${ }^{1}$. Therefore, guidelines advice prophylactic therapy during the first six months of $U^{2} T^{2}$. Colchicine $0.5-1 \mathrm{mg} /$ day is recommended. Whether $1 \mathrm{mg} /$ day colchicine is superior to $0.5 \mathrm{mg} /$ day is unknown.

Objectives: To examine the difference in gout flares in the first six months after initiation of ULT between 0.5 and $1.0 \mathrm{mg} /$ day colchicine prophylaxis.

Methods: Patients with clinical diagnosis of gout, a first outpatient visit between January 2010 and March 2018 and a follow-up of at least 6 months were included in a retrospective cohort study, conducted in two rheumatology centres in the Netherlands. Within this cohort, patients starting ULT and colchicine prophylaxis were selected. Difference in gout flare incidence density (ID) in the first six months after start of ULT between colchicine 0.5 and $1.0 \mathrm{mg} /$ day was analysed using Poisson regression, corrected for confounders. Secondary analyses included the proportion of patients reaching a target of serum urate acid (SUA) of $<0.36 \mathrm{mmol} / \mathrm{l}$ within the first six months.

Results: Of 2108 gout patients, 379 patients started ULT and used colchicine prophylaxis (table 1). ID of flares was 2.8 and 2.6 per patient year on colchicine 1.0 and $0.5 \mathrm{mg} /$ day respectively, resulting in an incidence rate ratio of 1.05 (95\% $\mathrm{Cl} 0.86-1.27$ ). Within the first six months $68 \%$ in the colchicine $1 \mathrm{mg} /$ day and $63 \%$ in the colchicine $0.5 \mathrm{mg} /$ day reached their target (difference $5 \%, 95 \% \mathrm{Cl}$ $-0.08-0.18)$
Table 1. Baseline patient, disease and treatment characteristics

\begin{tabular}{|c|c|c|}
\hline & \multicolumn{2}{|c|}{ Colchicine prophylaxis } \\
\hline & $0,5 \mathrm{mg} / \mathrm{day}(\mathrm{n}=275)$ & $1 \mathrm{mg} /$ day $(\mathrm{n}=104)$ \\
\hline Men, no. (\%) & $226(82 \%)$ & $88(85 \%)$ \\
\hline Age, years & $67.3(58.8-76.3)$ & $65.3^{*}(54.4-71.9)$ \\
\hline $\mathrm{BMI}, \mathrm{kg} / \mathrm{m}^{2}$ & $29.0(26.1-32.1)$ & $29.5(27.9-31.6)$ \\
\hline \multicolumn{3}{|l|}{ Comorbidity no. (\%) } \\
\hline Hypertension & $146(53 \%)$ & $54(52 \%)$ \\
\hline Diabetes Mellitus & $66(24 \%)$ & $24(23 \%)$ \\
\hline Hypercholesterolemia & $43(16 \%)$ & $15(14 \%)$ \\
\hline Renal insufficiency & $56(20 \%)$ & $18(17 \%)$ \\
\hline Crystal-confirmed diagnosis, no. (\%) & $197(72 \%)$ & 77 (74\%) \\
\hline $\begin{array}{l}\text { Serum urate acid at start ULT }(\mathrm{mmol} / \mathrm{l}) \text {, } \\
\text { mean } \pm \mathrm{SD}\end{array}$ & $0.51 \pm 0.11$ & $0.50 \pm 0.11$ \\
\hline \multicolumn{3}{|l|}{ ULT medication, no. (\%) } \\
\hline Allopurinol & $272(99 \%)$ & $103(99 \%)$ \\
\hline Benzbromaron & $2(0.6 \%)$ & \\
\hline Febuxostat & $1(0.4 \%)$ & $1(1 \%)$ \\
\hline
\end{tabular}

${ }^{*}$ Compared to colchicine $0,5 \mathrm{mg} /$ day, $\mathrm{P}<0.05$.

${ }^{*}$ No SD possible, $\mathrm{n}=1$.

Conclusion: Use of $1 \mathrm{mg} /$ day colchicine is not superior to $0.5 \mathrm{mg} /$ day as prophylaxis for ULT induced gout flares. For generalisability it should be noted that flare rates were not very high, probably due to the background ULT being characterised by a "start low go slow" approach. In this context colchicine $0.5 \mathrm{mg} /$ day is sufficient as prophylaxis. References:

[1] Seth R et al. J Rheumatol 2014;92;42-47.

[2] Richette P et al. Ann Rheum Dis 2017;76:29-42.

Disclosure of Interests: : Frouwke Veenstra: None declared, L.M. Verhoef: None declared, Lieke Nieboer: None declared, Alfons den Broeder: None declared, WingYee Kwok: None declared, Inger Meek: None declared, Frank van den Hoogen: None declared, Noortje van Herwaarden: None declared, Marcel Flendrie Grant/research support from: M. Flendrie has received grants from Menarini and Grunenthal., Consultant of: M. Flendrie has received consultancy fees from Menarini and Grunenthal. DOI: 10.1136/annrheumdis-2020-eular.3635

\section{THU0450 \\ OPTIMISTIC STATUS ASSOCIATES WITH COMPLIANCE TO URATE-LOWERING THERAPY IN GOUT PATIENTS}

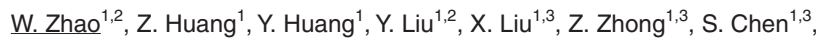
T. LI ${ }^{1}{ }^{1}$ Guangdong Second Provincial General Hospital, Department of Rheumatology and Immunology, Guangzhou, China; ${ }^{2}$ University of South China, Hengyang, China; ${ }^{3}$ Southern Medical University, The Second School of Clinical Medicine, Guangzhou, China

Background: Compliance to urate-lowering therapy (ULT) is poor in gout patients, which contributes to increased frequency of acute gout attacks, deposition of tophi and urate nephropathy [1]. Optimistic status is probably a potential and considerable factor affecting compliance to ULT in gout patients.

Objectives: To compare optimistic status between gout patients and healthy controls, and also between gout patients with good and poor compliance. Relationship between optimistic status and compliance to ULT, sUA target achievement of gout patients were assessed as well.

Methods: This was a monocentric and observational study which was performed from August 2018 to December 2019. Adult patients who met the 2015 gout classification criteria were included in this study. The healthy controls were individuals who were free of gout, hyperuricemia and other rheumatic diseases from the physical examination center of our hospital. Demographic data, including age, gender and education were collected from all individuals. Serum uric acid (sUA) were collected from gout patients at enrollment and again after 3 months. Disease duration of gout visual analogue scale (VAS) of pain were also assessed for gout patients at enrollment. Compliance to ULT was measured using the medication possession ratio (MPR) in the following 3 months. Poor compliance was defined as MPR $<0.8$ and good compliance was defined as $M P R \geq 0.8$. All subjects completed the life orientation test-revised (LOT-R) for optimistic status assessment.

Results: Five hundred and thirty gout patients and 307 healthy controls matched by age $(41.4 \pm 12.3$ vs. $42.1 \pm 9.3$ years), gender (male $97.1 \%$ vs. $95.1 \%$ ) and education (college graduated $54.2 \%$ vs. $58.0 \%$ ) were included in this study. Of the 530 gout patients, the mean disease duration was $5.7 \pm 4.9$ years, and $292(55.1 \%)$ patients' MPR were lower than 0.8 . There was no statistic difference in LOT-R between gout patients and healthy controls $(19.0 \pm 2.4$ vs. $19.2 \pm 2.5, P>0.05)$ (Table 1$)$. Gout patients with poor compliance (MPR<0.8) had higher level of SUA (525.5 \pm 138.0 vs. $471.2 \pm 152.5 \mu \mathrm{mol} / \mathrm{L}$ $\mathrm{P}<0.05)$, followup sUA $(450.1 \pm 154.5$ vs. $361.6 \pm 120.0 \mu \mathrm{mol} / \mathrm{L}, \mathrm{P}<0.05)$ and higher LOT-R $(19.6 \pm 2.6$ vs. $17.8 \pm 1.7, P<0.05)$ than those with good compliance (MPR $\geq 0.8$ ). Of the 292 gout patients with poor compliance, there were only $83(28.4 \%)$ patients achieved sUA target after 3 months, and their LOT-R were significantly lower than 